Educación Física y Ciencia, vol. 20, n 1 , e042, 2018. ISSN 2314-2561

Universidad Nacional de La Plata.

Facultad de Humanidades y Ciencias de la Educación.

Departamento de Educación Física

\title{
Educação do corpo e natureza: presciçoes da revista Educação Physica (Brasil, 1932-1945)
}

Medeiros, Daniele Cristina Carqueijeiro de; Quitzau, Evelise Amgarten

Cita sugerida: Medeiros, D. C. C. y Quitzau, E. A. (2018). Educação do corpo e natureza: prescrições da revista Educação Physica (Brasil, 1932-1945). Educación Física y Ciencia, 20(1), e042.

https://doi.org/10.24215/23142561e042 
Educação do corpo e natureza: presciçoes da revista Educação Physica (Brasil, 1932-1945)

Education of the body and nature: prescriptions in the magazine Eeducaçã Physica (Brazil, 1932-1945)

Daniele Cristina Carqueijeiro de Medeiros

Universidade Estadual de Campinas, Brasil

danieli_ccm@hotmail.com

Evelise Amgarten Quitzau

Instituto Superior de Educación Física, Universidad de la

República, Centro Universitario Regional Litoral Norte,

Sede Paysandú, Uruguay

equitzau@cup.edu.uy

\section{Resumo:}

Os processos de industrialização e urbanização, tanto na Europa quanto no Brasil, apresentam-se acompanhados de um novo olhar sobre a natureza. Antes vista como sombria e perigosa, a natureza e seus elementos passam a ser compreendidos como benéficos para a recuperação da saúde e da moral da população urbana, constituindo-se inclusive como prescrições médicas contra os males da cidade. Esse discurso de uma natureza benéfica tornou-se, cada vez mais, interlocutor de certa vertente do discurso médicohigienista, que passou a prescrever em seu receituário e recomendar em seus artigos o retorno à natureza. O objetivo deste artigo foi compreender as prescrições de práticas junto à natureza veiculadas por esse discurso médico na Revista Educação Physica, periódico especializado em esportes e educação física que circulou entre 1932 e 1945. Como resultados, percebemos que quase todos os volumes analisados da revista tratam de algum aspecto voltado à cura, regeneração ou divertimento em meio à natureza, seja através de exercícios físicos, da hidroterapia ou o contato com montanhas, alcançando seus cumes. Concluímos que esta revista corroborou com esta vertente do discurso médico higienista, ao associar as práticas em meio à natureza a valores morais, físicos e higiênicos que eram desejados para o fortalecimento dos corpos brasileiros do período.

Palavras-Chave: Natureza, Educação do corpo, Higiene, Revista Educação Physica.

\section{Abstract:}

The process of industrialization and urbanization in Europe and in Brazil were followed by new ways of looking at nature. Once considered dark and dangerous, nature and its elements start to be understood as beneficial for the recovery of both the health and moral of urban population, and were even prescribed by physicians as a means against urban illnesses. This discourse of a beneficent nature increasingly turned into the correspondent of certain branch of the medical hygienist discourses that started to write articles prescribing and recommending a return to nature. This paper aims to comprehend the prescriptions regarding practices alongside nature disseminated by the magazine Educação Physica, a specialized journal published in Brazil between 1932 and 1935. As a result, we realize that almost all the numbers we analyzed dealt with some aspect related to cure, regeneration or amusement amidst nature, whether through physical exercises, hydrotherapy or the contact with mountains, reaching their peaks. We conclude that this magazine supported this branch of the medical hygienist discourse by associating practices amidst nature to moral, physical and hygienic values desired for the strengthening of Brazilian bodies of that time.

KEYWORDS: Nature, Education of the body, Hygiene, Revista Educação Physica.

\section{INTRODUÇÃO}

O início dos processos de industrialização e urbanização da Europa entre os séculos XVIII e XIX marca o advento de novos olhares para a natureza. Embora uma mudança na sensibilidade com relação à natureza e seus elementos como a água, o clima e as montanhas já começasse a se operar no início do século XVII, com a emergência de uma vontade de desfrutar do espetáculo da natureza, das paisagens que exercem um novo fascínio incentivado pelos quadros e pela literatura romântica, ela somente se acentuaria, de certa forma, com o crescente galopar da industrialização que intensifica cada vez mais as fronteiras entre a natureza e a 
vida urbana, especialmente visível pela separação entre campo e cidade: há uma crescente repugnância pela aparência física dos aglomerados urbanos (Thomas, 1996).

O crescimento caótico e rápido das cidades exacerba as devassidões contidas em seu interior: é crescente o mau cheiro, o esgoto, a mortalidade, a aglomeração de pessoas nos passeios e nos bairros. De acordo com Foucault (2006) inúmeros aspectos da malha urbana deveriam ser melhorados para que a cidade se tornasse um ambiente menos insalubre e perigoso à população; dever-se-ia analisar os locais de acúmulo do que pudesse causar doenças ou epidemias, controlar a circulação do ar, das águas e mesmo das pessoas e organizar aquilo que deveria ser distribuído, como a água encanada e o esgoto. Nasce, assim, a necessidade de uma moral higiênica em que o médico se torna o responsável por pensar e ordenar a vida na cidade (Faure, 2008; Foucault, 2006).

Uma das vertentes deste discurso higiênico adota a natureza como a exata contradição aos malefícios urbanos: o campo é visto como um local moralmente mais benéfico do que a cidade (Thomas, 1996). Inspirada pela nova sensibilidade surgida a partir da literatura e das artes, essa medicina incentiva a experimentação das sensações proporcionadas por um local distante das clausuras, dos vícios, da sujeira. Entrar em contato com a natureza e seus elementos aos poucos passa a ser uma prática atestada pelos médicos como proveitosa e necessária à vida urbana (Rauch, 2001).

Os males urbanos que assolavam as cidades europeias chegaram ao Brasil tardiamente, já que o aumento populacional nas cidades se deu apenas na passagem do século XIX para o XX. Em cidades maiores, como São Paulo, a chegada dos imigrantes e de habitantes oriundos da zona rural favoreceu a consolidação do processo de industrialização e possibilitou que a cidade tomasse ares de um centro urbano, o que, por sua vez, atraía ainda mais moradores.

Os choques culturais e a percepção das diferenças tornaram-se fatores relevantes com esta nova confecção da malha urbana, e nem sempre eram relações fluidas. Para Alvim (1998) a estes confrontos culturais somavase o que poderíamos chamar de um "choque higiênico", uma vez que os hábitos de asseio e cuidados pessoais daqueles que chegavam à cidade se diferenciavam visivelmente daqueles que já viviam naquele meio.

Estas relações contribuíram para o advento de novas preocupaçóes, especialmente no que diz respeito aos aspectos sanitários (Souza, 2011). Neste mesmo período1, o higienismo chega ao Brasil mediante reinterpretações e reapropriações para que fossem guardadas as devidas proporções entre aquilo que era herdado do higienismo europeu e o que era realmente urgente e necessário no seio da saúde coletiva da população brasileira (Gois Junior, 2003).

Não se pode afirmar que o ideário médico higienista brasileiro era homogêneo em suas concepções de saúde e higiene moral (Gois Junior, 2013). Se por um lado havia entre os higienistas grupos que priorizavam a melhora das condições de vida e educação como principal caminho para o aperfeiçoamento da raça brasileira, por outro havia que defendiam medidas eugênicas mais enfáticas, como o controle da reprodução. As disputas ideológicas entre estes grupos se refletiam nas diversas questões que perpassavam a formação da raça brasileira, a melhoria das cidades e de seus fluxos, a mudança dos hábitos diários e higiênicos da população. Dentre estas preocupações, o distanciamento das cidades e aproximação com a natureza fazia-se presente neste pensamento.

As montanhas, praias e outros panoramas pitorescos ganharam logo o aval da medicina brasileira como possibilidades adequadas para a cura deste esfalfamento urbano. A natureza proposta e prescrita tinha ares de domesticação e ampla modelagem através das mãos humanas (Medeiros, 2012; Marras, 2004). Estações balneárias, estâncias hidrominerais, praias, prados, campos e montanhas: em diferentes periódicos produzidos em nosso país, inclusive naqueles voltados especificamente para questóes relacionadas à educação física e ao esporte, tais locais eram divulgados como ideais para o combate à fadiga e para o revigoramento das energias.

No Brasil, na passagem do século XIX para o XX, houve uma fértil cultura de revistas. Conforme Martins (2001), elas rapidamente se tornaram peça fundamental no dia-a-dia da população, já que se dispunham a 
assumir inúmeras funções nas relações sociais. É sabido que estes impressos se tornaram uma fonte bastante significativa de comunicação em um Brasil que se urbanizava, sobretudo por ser um veículo impresso com informações condensadas e de consumo fácil, com aparência frívola, divertida, recheada de imagens e que, desta forma, conseguia abarcar diversos tipos de leitores (Martins, 2001). Esta diversidade de tipos de leitores pode ser entendida como resultado da ampliação dos grupos que representavam uma cultura letrada no país e que, neste período, deixaram de ser limitados aos homens adultos das classes mais elevadas para incluir, por exemplo, mulheres, imigrantes, professores (Cruz, 2013). Neste sentido, não apenas a quantidade de impressos aumenta, mas também suas temáticas variam, de forma que a imprensa passa a dar visibilidade a diferentes práticas culturais, inclusive as esportivas.

Em meio a esta expansão dos periódicos em território nacional vemos surgir, especialmente a partir da década de 1930, revistas voltadas para a divulgação de aspectos científicos e pedagógicos relacionados aos exercícios físicos e do esporte. Segundo Lenharo (1986), o aparecimento de revistas especializadas nestes temas durante este período é reflexo do lugar central ocupado pelo corpo em diferentes instituições que acreditavam que, para se repensar e transformar a sociedade, era necessário tomar o corpo como um objeto de ação. Este argumento ganha mais força no caso brasileiro quando observamos que a criação destas revistas especializadas coincide com a constituição dos primeiros cursos civis de formação de professores de Educação Física nas cidades de Rio de Janeiro, São Paulo e Vitória (Melo, 1996; Borel, 2012; Gois Junior, 2017). Neste cenário, entre os periódicos que emergem em torno das temáticas da educação física, higiene e saúde, podemos destacar a revista Educação Physica, importante impresso fundado por iniciativa de dois professores de educação física, Paulo Lotufo e Oswaldo Murgel Rezende. Seu primeiro número foi lançado em maio de 1932, e o último em outubro de 1945, e ao longo deste período contou com a colaboração de personagens como o professor Américo Netto, da Escola de Educação Física do governo de São Paulo, representantes da Confederação Brasileira de Desportos e membros da Associação Cristão de Moços do Rio de Janeiro e da América do Sul, além de possuir representantes em países da Europa e África Portuguesa (Schneider, 2010; Schneider \& Ferreira Neto, 2008).

Esta revista, produzida em um período de significativas mudanças econômicas e sociais no Brasil, o Estado Novo, zela em suas páginas por um modelo de educação do corpo de homens e mulheres que forja o intento de enobrecer a raça brasileira e aumentar a força produtiva da nação, através dos esportes, das ginásticas e outros procedimentos voltados ao trabalho corporal. Segundo Goellner (1999) "seja pela ótica do trabalho, seja pelo lazer, o trabalho corporal é reconhecido como essencial ao desenvolvimento da nação porque capaz de mobilizar, simultaneamente, duas energias: a do corpo individual e a do corpo social” (p. 3).

Dado seu pioneirismo e sua importância na constituição do campo da educação física e dos esportes no país, a revista Educação Physica vem sendo objeto de diferentes estudos ao longo dos últimos anos, que a abordam das mais variadas maneiras, utilizando-a tanto como fonte para o estudo de temas referentes à educação física e ao esporte, como objeto de investigação em si mesmo, analisando as estratégias editoriais por trás de sua produção. Diversos autores trabalharam com as páginas dessa revista no cenário da história da educação física e dos esportes no Brasil, o que a torna um importante interlocutor de numerosos assuntos que permearam a formação dessa disciplina e da introdução progressiva dos esportes como elementos de educação dos corpos no Brasil, entre as décadas 1930 e 1940.

Gois Junior e Lovisolo (2005) analisaram, nos discursos veiculados por esta revista, as tendências do discurso do movimento higienista nas décadas de 1930 e 1940 no Brasil. O objetivo dos autores foi mostrar que as correntes teóricas deste movimento, determinadas pelas áreas da medicina e biologia, influenciaram as discussões sobre educação física no Brasil. Gois Junior, Melo e Soares (2015) estudaram, nas páginas do periódico, o debate que se fez na educação física brasileira dos anos 1930 sobre a melhor forma de educar os corpos, quer seja, a ginástica ou o esporte. Os autores perceberam que, embora as reportagens e os artigos de opinião exaltassem alguns benefícios do esporte, alguns outros discursos propagados na revista criticavam os exageros do esporte e os excessos de "estrangeirismo". 
A respeito de uma "construção do homem novo" brasileiro, Schneider e Ferreira Neto (2008) investigaram as disputas entre diferentes padróes culturais que se construíram nas páginas dessa revista, entre 1932 e 1945, a respeito da representação do brasileiro do século XX. De acordo com os autores, havia uma tendência à americanização da educação brasileira, e essa tendência era bastante evidente na educação física. A modernidade, representada pelos modelos europeus e norte-americanos, era desejada e ancorada nas práticas esportivas, que recheavam as páginas da revista aqui citada.

Goellner (2000a, 2000b) analisou as páginas desta revista especialmente no que tangia à educação do corpo das mulheres e à forma como elas eram representadas. Para a autora, esta revista contribuiu na divulgação de um discurso de certa forma padronizado a respeito do corpo da mulher nas décadas de 1930 e 1940 . Ao mesmo tempo em que eram indicadas as práticas esportivas, de aventura, de ginástica, as mulheres deveriam realizá-las de forma recatada, sem promiscuidades e nem excessos, para que estas práticas corporais não inibissem seus verdadeiros propósitos: serem belas, maternais e femininas.

Scheneider $(2004 ; 2010)$ tomou este impresso como objeto de pesquisa, e analisou seus discursos, tendências e intencionalidades. $\mathrm{O}$ autor ressalta que a revista tinha como intenção não apenas sugerir ou divulgar práticas esportivas e de educação física, mas, especialmente, persuadir, estimular e fazer com que as pessoas realizem estas práticas. Assim, essa revista funcionou como uma estratégia de conformação de práticas e dispositivo de produção de sentidos.

Os temas sobre os quais a publicação versava giravam em torno de debates como a higiene, a educação, o valor dos exercícios físicos, o sentimento de nacionalidade, o progresso e a moral (Schneider, 2010). No número que celebra seus dez anos de existência, a própria revista organiza um resumo dos assuntos por ela tratados (Primeiro decênio, 1942). Neste levantamento, os dois assuntos são a higiene e a saúde, o que confirma estas temáticas como as duas mais frequentes de publicação em seu primeiro decênio. Ressalta-se que um dos temas neste decênio foi o excursionismo, o que nos fornece um indício da importância dada pelos colaboradores da revista às práticas corporais junto à natureza. Danailof (2013), ao estudar os parques infantis do Estado de São Paulo, já havia encontrado ecos de certa indicação de espaços educativos em meio à natureza neste periódico, ainda que esses discursos viessem, em suas páginas, rodeados de críticas pela falta de investimento na rede pública de ensino.

Buscando seguir a lógica deste levantamento realizado pela própria revista, Schneider (2010) organizou um temário similar tomando como fontes as publicações posteriores à edição comemorativa de maio de 1942, englobando os números 64 a 88 da revista. Este autor estipulou nove eixos em foram agrupadas as matérias da revista: esportes; saúde; alimentação; fisiologia e treinamento; fundamentos pedagógicos; filosofia; acampamento e turismo; bibliografia e literatura; e outros. Todos são devidamente especificados e, no eixo acampamento e turismo, que corresponde a 15\% das matérias publicadas,"estão elencados os títulos que agrupavam as matérias que versavam sobre excursionismo, agenda de viagens, colônias de férias e escotismo", (Schneider, 2010, p. 137). O aparecimento dessas repostagens ligadas à natureza nos diferentes períodos da existência da revista, e representando uma porcentagem significativa de entre os temas por ela veiculados, nos levaram a uma série de questóes. De que forma os discursos de retorno à natureza eram promovidos em suas páginas? Estes discursos se ligavam às intenções da revista, que, como vimos, se associavam a vertentes higienistas e até eugênicas? A volta à natureza e o ideário de vida ao ar livre tinham relação com a intenção, expressa por autores ligados ao periódico, de elaborar diferentes propostas de educação do corpo para o novo corpo do homem e da mulher brasileiros?

Com uma publicação não constante, embora autodenominada mensal, a revista alcançou 88 números, considerado um grande marco para um periódico desta época que se dedicava a uma temática especializada, que se comprometia "com a divulgação da ideia de que a Educação Física e os esportes são fundamentais na formação da juventude e na preparação de mulheres e de homens para o enfrentamento de obstáculos inerentes à vida cotidiana, urbana e moderna" (Goellner, 1999, p.4). Considerando a importância desta revista na circulação de conhecimentos relacionados ao corpo e à Educação Física, bem como o espaço 
ocupado em suas páginas por artigos referentes à temática da vida ao ar livre, este estudo tem como objetivo analisar as prescrições de práticas corporais junto à natureza veiculadas pela revista Educação Physica.

As revistas utilizadas para esta pesquisa foram encontradas nas Coleções Especiais da Biblioteca Asdrúbal Ferreira Batista, da Faculdade de Educação Física da UNICAMP. Do total de 88 exemplares que foram publicados ao longo dos treze anos de existência da revista, foram encontrados nesta coleção 69 exemplares, o que significa que pudemos analisar $78 \%$ dos números publicados. Nessas revistas, analisamos especificamente os discursos voltados ao bom aproveitamento da natureza, que abarcavam desde prescrições de passeios, indicação de uso de alguns elementos naturais, até receituários médicos que incluíam os elementos da natureza como medicamentos indicados para a cura.

\section{CIDADE X NATUREZA: O SOL, AS ÁGUAS E AS MONTANHAS COMO ELEMENTOS DE CURA}

No combate às mazelas das cidades brasileiras que atingiam seu esplendor na aurora do século XX, como a já exemplificada São Paulo, os médicos higienistas e sanitaristas ganharam destaque, buscando produzir locais e modos de vida diferentes, mais benéficos moral e higienicamente do que aqueles assumidos pela maioria da população.

O ideal de corpos belos, fortes e úteis era caro à formação da nova sociedade que se desejava para um Brasil que se urbanizava e industrializava. A cidade figurava como um local perverso e sujo, ainda que berço da nova civilidade brasileira, e ameaçava o vigor físico, a saúde, o progresso e a civilização. Era preciso impedir que o estilo de vida urbano se tornasse responsável por definhar os corpos e os nervos de seus habitantes.

A fadiga, um dos grandes vilões já apontados na vida urbana europeia, também emergia nas páginas da revista Educação Physica como um componente importante no desgaste cotidiano proporcionado pela cidade:

A vida moderna, especialmente nas grandes cidades, impõe um desgaste físico extraordinário. É o "struggle for life” — tudo pela vida - dos ingleses, que esgota o sistema nervoso e rebaixa o "standard" orgânico, encurtando a existência humana (Scolnik, 1942, p. 34)2

A vida na cidade afastava o contato dos habitantes com as fontes produtoras de energia e de saúde, embora fosse o local prioritário para um estilo de vida moderno. Estabelece-se, então, um distanciamento entre a vida na cidade e a vida na natureza. Em artigo intitulado "Volta à natureza", o autor, Braulio Laurencena Drescher, diz que o luxo proveniente da cidade faz com que os indivíduos percam suas qualidades físicas e morais, o que é atrelado diretamente à decadência física da raça brasileira. $\mathrm{O}$ autor continua dizendo que os resultados da vida urbana não são agradáveis, e que as consequências são inúmeras, destacando:

a) fadiga, irritabilidade, nervosidade, histeria, demência

b) desordens do fígado, rins e systema circulatório

c) esforço dos sentidos especiaes como a vista, os ouvidos, etc.. especialmente nas indústrias

[...]

Transtorno do systema digestivo, produzidos por alimentação impropria

Falta de ar livre e sol devido às más vivências (Drescher, 1938)

É imperativo neste discurso que o habitante das cidades deve abandonar os ritmos urbanos, mesmo que por um momento, para se voltar para outras relações, que começam a ser explicitadas a partir do contato com a natureza. Os fatores que deveriam levar um habitante da cidade a afastar-se das obrigaçóes diárias deveriam ser, de fato, a fadiga mental e o desgaste físico proporcionados pelas atividades; os tempos prejudiciais à vida, poderiam e deveriam ser quebrados com uma viagem de volta à natureza: 
O turista deve procurar "renovar-se" não só proporcionando aos seus próprios olhos espetáculos e objetos novos, como procurando levar uma vida, embora por pouco tempo, diferente de todas as "Viagens em zig-zag", é necessário "suscitar contrariedades eficazes" que se obteem com preocupações pessoais, de índole muito diversa das que sentimos comumente porque se referem aos esforços físicos que manteem o corpo e a alma em atividade, para suportar privações e transpor obstáculos.

Escalar cumeadas com o fim de proporcionar-se o espetáculo incomparável que se contempla das alturas; caminhar quilômetros buscando as nascentes dos rios e dos riachos; descer ao fundo dos barrancos e precipícios, são causa de esforços prolongados, de sofrimento mesmo, mas sofrimento doce, que obrigam o organismo a intensificar suas funções e acabam em prazer físico e espiritual (Scolnik, 1942 , p. 34)

Um dos períodos eleitos pelo discurso médico para que se desse essa "fuga" do meio urbano rumo à natureza eram as férias. As correntes médicas que se ocupavam da melhoria do corpo e da produtividade do trabalhador impunham a necessidade deste período de descanso como compensação ao esfalfamento causado pelas intensas rotinas no meio urbano-industrial. Setores mais radicais da moralização dos costumes e higienização das cidades e da sociedade, como os eugenistas, também aprovavam o afastamento da população para locais junto à natureza nos períodos de férias, bem como em outros momentos, como os finais de semana. Renato Khel3, adepto de uma eugenia classificada como negativa ( Gois Junior , 2003), assinou diversos artigos na revista Educação Physica em que exaltava os benefícios de um período de férias distante das cidades:

Não há povo civilizado que não conheça e não pratique esta importantíssima obrigação sanitária de ausentar-se, todos os anos, das ocupações, indo passar uns dias à beira mar ou nas montanhas, respirar ares diversos, descansar a vista em paisagens diferentes, poupar os órgãos das mesmas intoxicações; em suma, criar novas fôrças, fortalecer-se, rejuvenescer-se, para um novo ano de lutas. (Kehl, 1941b, p. 27)

A natureza que auxilia as prescrições médicas, como as propostas por Khel, não é aquela selvagem tampouco aquela que apresentava ares rurais: seus elementos, quer seja o sol, as montanhas ou as águas eram tratados com um rigor científico que caracterizava o positivismo como ideologia médica dominante (Soares, 1990, 1994; Luz, 1982). Assim, um caráter prescritivo pautado e legitimado pela ciência é notado nas páginas da Revista Educação Physica ao tratar das questões relacionadas aos exercícios físicos e ao contato com os elementos naturais, em especial as águas, a luz do sol e os ares das montanhas.

O sol como importante provedor de recursos energéticos para os tecidos é um elemento resgatado pelo "novo naturalismo do século XX", conforme Feinmann (1940). O autor diz que os banhos de sol eram grandes auxiliares da medicina grega e que este deveria ser utilizado para o revigoramento. A diferença é que isso não aconteceria mais de forma empírica, e sim por meio de sólidos conhecimentos científicos - a chamada helioterapia:

O sol age terapêuticamente sôbre grande número de estados mórbidos. Antigamente, as curas solares eram feitas de modo empírico e, mesmo assim, com reais proveitos; atualmente elas se assentam em experiências e fatos indubitáveis, após as conquistas de Finsen e de seus continuadores, estabelecendo-se regras perfeitamente científicas, constituindo-se o novo ramo da arte de curar denominado helioterapia (Kehl, 1941, p. 44)

Carter (2012), ao estudar o contexto inglês, afirma que o uso da luz do sol com finalidades clínicas começou a surgir já nas últimas décadas do século XIX. Nas primeiras décadas do século XX, esta prática passou a ser pensada com grande ênfase na questão da eficácia, sendo considerada um importante aliado no tratamento de doenças como a tuberculose e o raquitismo, desde que aplicada de maneira correta e, de preferência, com acompanhamento de profissionais, os helioterapeutas. Ao se tornar uma ciência, a exposição a este elemento deveria seguir regras e leis que equacionassem o seu uso, dividindo os princípios em variáveis gradativas e diferentes quantidades. Este movimento de medicalização dos raios solares pode ser observado, também, no Brasil. No artigo "Como se devem tomar os banhos de sol”, as regras para a prática da helioterapia são explicitadas em tópicos, que contém as indicações e contraindicações, o tempo adequado e a gradação de exposição ao longo dos dias: 
$1^{\circ}$ No primeiro dia se expõe unicamente a primeira zona (pés e pernas) á acção directa do sol, durante 10 minutos

$2^{\circ}$ No segundo dia, repete-se o que se fez no primeiro e immediatamente depois se expõe a segunda zona, sem cobrir a primeira. Ambas ficarão expostas durante 5 minutos. Quer dizer pois, que, o dia da $2^{\mathrm{a}}$ zona recebe -5 minutos de banho e a segunda só 5

$3^{\circ}$ No terceiro dia, repete-se o que se fez no segundo [...] (Como se devem... 1937, p. 94)

As queimaduras e contraindicações do uso do sol também apareciam como fatores relevantes na divulgação deste elemento natural. As diferenciações entre os raios ultravioletas e infravermelhos já estampavam as discussões das revistas, definidos como as causas recém descobertas da insolação e dos malefícios do sol. Ainda assim, a exposição ao sol era indicada, com ressalvas e cuidados para aqueles que desejavam usufruí-lo:

Entre as enfermidades produzidas pela acção dos raios solares, temos a insolação, por exposição do corpo humano á acção directa de um sol intenso durante alguns minutos. É frequente nas praias balneárias, em que a maioria das pessoas comparece sem nenhuma experiência, com um objectivo apenas: queimar-se ao sol, sem tomar nenhuma precaução. Observam-se, ás vezes, casos, graves em virtude das pessoas exporem-se, em demasia, ao sol. (Etchevarne, 1938, p. 26)

Outro fator considerado relevante para o bom usufruto dos banhos de sol eram os acessórios adequados para a boa prática da helioterapia: óculos, chapéus, cremes e trajes específicos adentraram o universo do contato cientifizado com a luz do sol (Soares, 2011).

A extensa difusão que os óculos escuros contra o sol já encontravam, funcionando principalmente como um item de moda, preocupava de certa forma aqueles que indicavam a helioterapia. De acordo com Grotacos (1938), a difusão deste item deveria se dar pela noção higiênica proporcionada principalmente através das revistas científicas, e não apenas como um acessório da vestimenta moderna.

Além dos óculos, outras preocupações deveriam acompanhar o vestuário dos banhistas, para a proteção dos excessos ocasionados pelos raios solares:

Para que a pele possa suportar as exposições prolongadas, sem prejuízos, é aconselhável o uso dos cremes ou líquidos que a protejam. [...]. Convém recordar que é perigoso receber os raios solares sôbre a nuca ou na parte superior do pescoço, de modo que quando não se tem um amplo chapéo, é preciso proteger com um lenço grande ou com uma toalha (Regras, 1939, p. 33)

A progressão utilizada ao longo dos dias e a incidência dos raios de sol sobre o corpo eram questóes centrais da helioterapia, ao ponto de tabelas serem montadas para auxiliar os banhistas. Pacífico Castelo Branco aponta em artigo intitulado "A técnica dos banhos de sol" (1939) uma tabela de subtítulo "esquema de insolação progressiva de Rollier”, que possuía as variáveis: dias, zona do corpo e duração, que aumentavam progressivamente, conforme o banhista se tornasse mais adaptado àquele elemento.

A água foi outro elemento que ocupou lugar de destaque nas páginas da revista Educação Physica, principalmente na vertente mais ligada à higiene pessoal, os banhos. A recente descoberta microbiana alavancara a noção de que a pele era um invólucro permeado de imundícies, o que elevava a importância do banho como fator higiênico. Além da limpeza externa, o banho serviria para evitar a propagação dos "germes", agentes malignos prontos para invadir o organismo:

Calculando-se o número médio de micróbios deixados na banheira após o banho e tendo em conta a superfície do tegumento cutâneo, chegou-se à conclusão de que podem existir 40.000 em cada centímetro quadrado de pele. [...]. Além de imundície, a falta de banho diário representa um atentado às narinas estranhas, à própria saúde, visto permitir a população de germens patogênicos, sempre prontos a invadir o organismo incauto na primeira oportunidade (Kehl, 1941b, p. 26)

Há, neste mesmo artigo, uma diferenciação entre os usos das águas quentes e frias na tônica do organismo. O banho frio deveria ser tomado todos os dias pela manhã, de forma breve, para que não houvesse perdas excessivas de calor. Os benefícios seriam sentidos depois do banho: "a pele aquece-se e colore-se de novo, a respiração torna-se ampla, o pulso cheio, o indivíduo sente legítimo estado de euforia, um bem-estar agradabilíssimo" (Kehl, 1941b, p. 26). 
Já os banhos mornos, com temperatura até $30^{\circ} \mathrm{C}$, só eram aconselhados aos velhos e às crianças, por sua ação calmante e sedativa, apropriadas para o uso daqueles com os corpos estafados. $\mathrm{O}$ autor desaconselha o uso de banhos acima de $32^{\circ} \mathrm{C}$, já que esta temperatura ao invés de revigorar o corpo, apenas servia para o deixar amolecido. Com relação aos banhos de vapores, banhos turcos ou russos, afirmava que estas práticas serviriam apenas para o luxo ou a apreciação da novidade (Kehl, 1941).

O modelo de banho mais divulgado nas páginas da revista era o banho de mar, aliado ao clima marítimo proporcionado por uma estadia nas praias. O uso destes locais, que ficavam apinhados de visitantes no verão, deveria ser feito com cautela pelos banhistas. A primeira regra que deveria ser observada era o tempo a ser guardado entre a refeição e o banho de mar, contando "uma ou duas horas depois de uma ligeira refeição, e três ou quatro horas após um almoço ou jantar fortes, com excepção daquellas pessoas que sómente podem tomar banho em jejum" (Boigey, 1937, p. 72).

A forma adequada de banhar-se deveria seguir à risca as indicações. $\mathrm{O}$ ideal era que todo o corpo, inclusive a cabeça, fosse submergido ao mesmo tempo; uma vez dentro do mar, o banhista deveria abaixar-se e levantarse alternadamente, ou então nadar durante todo o tempo que o banho durasse (Boigey, 1937). De modo geral, as indicações para o uso das praias e dos banhos de mar podem ser sintetizadas com o seguinte trecho:

$1^{\circ}$ - Procurar passar, pelo menos, três semanas de descanso.[...]

$2^{\circ}$ - Tomar cada dia quatro banhos: de ar, que durará todo o dia; de mar, que durará 5, 10, até 15 minutos; de movimentos (exercícios), que durará uma hora; e finalmente banho de sol, que durará de 5 até 30 minutos

$3^{\circ}$ - Vestir-se racionalmente [...]

$7^{\circ}$ - Deitar-se cedo e dormir de 8 a 10 horas, completando-as com a sesta. Tomar um banho de chuveiro para retirar todas as partículas de areia que tenham aderido à pele. (Spes, 1943, p. 36)

As águas quentes tinham indicações de uso totalmente controladas, a começar pelo local de seu usufruto, uma vez que se reservava a estabelecimentos termais, sob a vigilância de funcionários que cuidavam para que as prescrições médicas fossem respeitadas. Para Pathault (1940), a questão técnica dos banhos era o que existia de mais importante para os resultados futuros, e um profissional treinado no manejo das banheiras e das práticas acessórias era parte fundamental.

Ainda conforme Pathault, a hidroterapia funcionava como um meio para a obtenção da saúde, e não como um fim. Logo, era necessário cuidar do que vinha antes e depois, atentando-se aos detalhes, como a temperatura do ambiente e da água, e os procedimentos após o fim dos banhos. É desta forma que o autor explica o insucesso de alguns tratamentos:

É justamente porque não se explica ao pessoal nem aos ajudantes o sentido e o valor dêsses fenômenos, que vemos tantos erros cometidos diariamente. Muita gente que toma seu banho ou sua ducha, retira-se do estabelecimento sem outro beneficio que uma satisfação passageira, o que não é, de modo algum, uma ação profunda e durável. Não obtém, dêsse modo, a décima parte das vantagens que poderiam obter si houvessem sabido utilizar-se melhor dos meios, sejam sedativos, sejam estimulantes, que se tem o direito de conquistar (Pathault, 1940)

As ações curativas das águas quentes são expostas em outro artigo, intitulado "O tratamento hidroterápico na paralisia infantil". O autor Galdino Nunes Vieira atribui o aumento nos casos de paralisia infantil às relações da vida moderna, que degeneram física e moralmente os seres humanos. $\mathrm{O}$ tratamento da paralisia com as águas termais era eficaz por conta de três características. A primeira eram as ações térmicas proporcionadas pelas águas quentes; a segunda, as ações mecânicas como a ginástica funcional e as massagens; e a terceira as ações nervosas, que se davam pelo estímulo proporcionado ao sistema nervoso com a imersão nas águas (Vieira, 1944). O artigo sugere que um conhecimento científico mais aprofundado sobre a utilização da água como cura para diferentes males vinha se difundindo na mesma medida em que os saberes médicos passavam a se sobrepor às práticas populares. 
Além dos raios solares e das águas, as montanhas também ganharam destaque nas páginas da revista Educação Physica, principalmente através do excursionismo, da marcha e dos acampamentos, atividades possíveis e amplamente divulgadas pelo periódico.

Em um artigo de Hollanda de Loyola intitulado "Montanhismo", é exaltado o caráter utilitário desta prática, digno de ser utilizado para a educação integral da juventude. Além do prazer sadio da vida ao ar livre em contato com a natureza, este "desporto" era indicado por suas qualidades morais, como o "robustecimento da saúde e a recreação do espírito" (Loyola, 1942, p. 40). O autor destaca que a montanha deveria ser o cenário escolhido por proporcionar beleza às vistas e ar puríssimo, além da virtude moral de possibilitar que durante a subida o montanhista vencesse os medos que surgissem (Loyola, 1942).

A marcha nas montanhas se mostrava um exercício físico diferente em esforço daquele realizado no plano, e exigia alguns cuidados. Goulart (1940) explica em seu artigo que os abusos cometidos pelos atletas, como percorrer distâncias maiores do que poderiam ou utilizar equipamentos inadequados quase minaram o interesse da população por este esporte. Para o autor, ao extrapolarem os limites do próprio corpo, os montanhistas deixavam de aproveitar as maiores vantagens das montanhas, como a paisagem do percurso. Desta forma, exaltou as medidas de segurança tomadas em relação a esta prática:

Uma razoável moderação, sabiamente imposta aos imprudentes ou inconscientes por intermédio de instruções aos guias, e mesmo ordens terminantes para não se permitir imprudências, puzeram felizmente côbro á fúria daqueles que pensavam haver glória em correr e vencer maratônas montanhistas, mesmo sem gozar as principais vantagens da montanha que são: o ar puríssimo, uma insolação preciosa e rara e a tranquilidade tônica das grandes altitudes. (Goulart, 1940, p. 12)

A principal indicação das matérias da revista a este esporte era aquela de viés patriótico. O excursionismo e o montanhismo foram atividades prescritas por despertarem o interesse da população com relação às belezas naturais do país (Azambuja \& Silva, 1945). Este foi o grande motivo para que o Conselho Nacional de Desportos publicasse, no número 77 da revista, um parecer sobre o excursionismo, no qual foram exaltados o caráter higiênico, moral e físico desta prática, ligados à ideia de que ela possibilitaria um real conhecimento sobre as realidades físicas do país.

A própria revista tentaria se incumbir de divulgar os recantos pitorescos do país em colaboração com os clubes excursionistas brasileiros. Na seção "Sugestões para o fim de semana", criada em 1944 para dar suporte a esta iniciativa, o local divulgado foi o recreio dos bandeirantes, no Rio de Janeiro (Sugestões, 1945). Na edição seguinte (número 87), o local pitoresco digno de ser visitado a estampar as páginas da matéria foi o Corcovado. No seguinte, e último a ser publicado pela revista, a sugestão foi a visita ao Pão de Açúcar, que deveria ser feita não apenas com os bondinhos, pois "um verdadeiro excursionista não desposará o ensejo de escalar as faldas do penhasco...” (Sugestões, 1945, p.29).

Apesar das críticas à falta de incentivo governamental ao desporto, Aroldo Moreira, secretário administrador do Centro Excursionista, aponta que a criação da UBE (União Brasileira de Excursionismo) fora um passo muito importante na divulgação do desporto, e que a falta de propaganda poderia deixar de ser um empecilho agora que o excursionismo havia se tornado mais organizado (Moreira, 1945). Por fim, na mesma edição, M. S. Coelho exalta uma ação da UBE que promoveu a visitação à Pedra da Gávea, em que dezenas de jovens excursionistas realizaram atividades no local (Coelho, 1945). Esta ação pode servir para ilustrar o escopo de atividades que teriam sido oferecidas pela UBE, entretanto, não é possível determinar qual era a abrangência das ações propostas pela União.

\section{CONSIDERAÇÕES FINAIS}

O que se percebe ao olhar para as 69 edições da Revista Educação Physica utilizadas neste trabalho é que há uma ideia recorrente de uma volta reparadora à natureza. Os artigos, que se pronunciam quanto ao destino escolhido, o tempo de repouso, as práticas corporais a serem realizadas, preconizavam que em meio à natureza 
era possível cultivar aspectos morais, físicos e higiênicos que não eram mais encontrados nas cidades. É possível afirmar, portanto, que a natureza e seus destinos e elementos foram amplamente utilizados como aliados às intenções editoriais da revista, quer seja, educar de forma diferente o homem e a mulher brasileiros, através de novas normas morais e sanitárias.

Ao folhear suas páginas, percebemos que as águas, os raios solares e as montanhas, com seus ares mais salubres e percursos desafiadores, desde que utilizados de forma racional, segundo prescriçóes muito bem delineadas pela medicina, emergem como importantes espaços de regeneração física e moral frente aos males e vícios impostos pelos meios urbanos. A natureza era promovida nas páginas da revista de diversas formas: através de indicações de viagens rumo a destinos em meio à natureza; da indicação da maneira correta de se fazer as malas e procurar pelos destinos; da indicação da quantidade dos elementos a se ter contato, como nos raios de sol, água do mar e águas termais. Outras formas de indicar a natureza tinham como aliado o discurso do bom aproveitamento das férias, e de que este tempo deveria ser vivenciado longe das cidades, em locais rodeados pela natureza.

É preciso frisar também que não se falava ali de qualquer natureza: não havia indicações de destinos perigosos ou aqueles em meio ao mundo rural, sinônimo de doença e moleza. A natureza indicada nas páginas da revista era aquela já analisada, medida e quantificada pela ciência, que deveria ser aproveitada a contagotas. Afinal, aqueles que a procuravam deveriam dosar seu uso, para que não se exigisse demais dos corpos nos tempos de descanso, mas que, ao mesmo tempo, não se deixassem levar pela ociosidade. Assim, é possível afirmar que esta natureza só foi possibilitada nas páginas das revistas depois de uma minuciosa investigação científica a respeito dos elementos naturais presentes nos discursos.

Podemos concluir, portanto, que as revistas de vulgarização científica serviram para impulsionar o turismo em meio à natureza, alinhando essa prática aos ditames médicos e higiênicos.

\section{REFERÊNCIAS}

Alvim, Z. (1998) Imigrantes: a vida privada dos pobres do campo. In: NOVAIS, F. A. (coord.); Sevcenko, N. (org.) História da vida privada no Brasil 3: República: da Belle Époque à época do rádio. São Paulo: Companhia das Letras.

Azambuja, O.; Silva, F. (1945) Excursionismo e montanhismo - cinco grandes conquistas. Educação Physica, (87), 11-14.

Boigey, M. (1937) A influencia hygienica do mar e dos banhos de mar. Educação Physica, (13), 70-73.

Borel, T. (2012) Processos de formação docente na constituição histórica da educação física escolar no Espírito Santo, nas décadas de 1930 e 1940. (Dissertação mestrado) - Centro de Educação, Universidade Federal do Espírito Santo, Vitória.

Branco, P. C. (1939) A técnica dos banhos de sol. Educação Physica, Rio de Janeiro, n. 37, p. 12, ano X.

Carter, S. (2012) The medicalization of sunlight in the early twentieth century. Journal of Historical Sociology, 25(1), 83-105

Coelho, M. S. (1945) O montanhismo e a juventude. Educação Physica, (87), 34-35.

Como se devem tomar os banhos de sol (1937). Educação Physica, Rio de Janeiro, n. 11, p. 94.

Cruz, H. F. São Paulo em papel e tinta: periodismo e vida urbana 1890-1915. São Paulo: Arquivo Público do Estado de São Paulo, 2013.

Danailof, K. (2013) A 'educação physica' nos parques infantis de São Paulo (1935-1938). Movimento Online,19, 167-184.

Drescher, B. (1938) Volta à natureza. Educação Physica, (17), 67.

Etchevarne, C. (1938) Afecções provocadas pelo sol. Educação Physica, (14), 25-26. 
Faure, O. (2008) O olhar dos médicos. In: Corbin, A; Courtine, J.J.; Vigarello, G. História do Corpo 2: da Revolução à Grande Guerra. Petrópolis, Brasil: Vozes.

Feinnman, E. (1940) Vida ao sol. Educação Physica, (41), 21-22.

Foucault, M. (2006)Microfisica do poder. 22. ed. Rio de Janeiro, RJ: Graal.

Goellner, S. V. (1999) Bela, maternal e Feminina: imagens da mulher da revista Educação Physica. (Tese doutorado). Faculdade de Educação, Universidade Estadual de Campinas, Brasil.

Goellner, S. V. (2000) A educação física e a construção de imagens de feminilidade no Brasil dos anos 30 e 40. Movimento, 7(13), 61-70.

Goellner, S. V. (2000) Mulheres em movimento: imagens femininas na Revista Educação Physica.Educação e Realidade, 2(25), 77-94.

Góis Junior, E.; Lovisolo, H. R. (2003) Descontinuidade e Continuidades do Movimento Higienista no Brasil do Século XX. Revista Brasileira de Ciências do Esporte (Online), 25. 41-55.

Góis Junior, E.; Lovisolo, H. R. (2005) Educação Física e concepções higienistas sobre raça: uma reinterpretação histórica da Educação Física dos anos de 1930. Revista Portuguesa de Ciências do Desporto, 5, 322-328.

Góis Junior, E. (2017) A institucionalização da Educação Física na imprensa: a construção da Escola Superior de Educação Physica de S. Paulo na década de 1930. Movimento, 23, 701-714.

Góis Junior, E. (2013) Revista Educação Physica e a higiene dos corpos (1932-1945). Recorde: Revista de História do Esporte, 6, 1-13.

Góis Junior, E.; Soares, A. J. G. ; Melo, V. A. (2015) Para a construção da nação: debates brasileiros sobre educação do corpo na década de 1930. Educação e sociedade, 36, 343-360.

Goulart, G. (1940) A marcha na montanha. Educação Physica, (30), 12.

Grotacos. (1938) A moda dos óculos escuros contra o sol. Educação Physica, (16), 16-17, mar.

Kehl, R. (1941a) A luz solar. Educação Physica, (55), 44.

Kehl, R. (1941b) O banho. Educação Physica, (61), 26-28.

Kinoshita, C. T. (2013) Um d. Quixote cientifico a pregar para uma legiäo de panças: os manuais escolares de higiene à sombra da eugenia (1923-1936). (Dissertação mestrado) -Faculdade de Educação. Universidade Estadual de Campinas, Campinas, Brasil.

Lenharo, A. (1986) Sacralização da política. Campinas, SP: Papirus: Editora da Unicamp.

Loyola, I. (1942) Montanhismo. Educação Physica, (62), 40-43.

Luz, M. T. (1982) Medicina e ordem política brasileira: politicas e instituiçôes de saúde, (1850-1930). Rio de Janeiro, RJ: Edições Graal.

Marras, S. (2004) A propósito de águas virtuosas: formação e ocorrências de uma estação balneária no Brasil. Belo Horizonte, MG: Editora da UFMG.

Martins, A. L. (2001) Revistas em revista: imprensa e praticas culturais em tempos de republica, São Paulo (1890-1922). São Paulo, SP: Edusp; FAPESP; Imprensa Oficial do Estado.

Melo, V.A. (1996) Escola Nacional de Educação Física e Desportos: uma possivel história. (Dissertação mestrado) Faculdade de Educação Física, Universidade Estadual de Campinas, Campinas.

Medeiros, D. C. C; Soares, C.L. (orient.). (2012). Por que procuras a natureza? A educação do corpo e as viagens de férias às estâncias hidrominerais (1930-1940)

Moreira, A. (1945) Educação técnica no excursionismo.Educação Physica,(87), 39-40.

Pathault. (1940) A técnica do banho. Educação Physica, (41), 58.

O Primeiro Decênio De “Educação Física”. (1942) Educação Physica, Rio de Janeiro,nº 64, p 48.

Rauch, A. (2001) As férias e a natureza revisitada (1830-1939). In: Corbin, A.; Csergo, J. História dos tempos livres: o advento do lazer. Lisboa, Portugal: Teorema.

Regras para os banhos de sol. (1939) Educação Physica, Rio de Janeiro, n. 27, p. 33. 
Rocha, H. H. P. (2003) A higienização dos costumes: educação escolar e saúde no projeto do Instituto de Hygiene de São Paulo.Campinas: Mercado de Letras; FAPESP.

Scolnik, J. (1942) A respeito de turismo e turistas. Educação Physica, (67), 34.

Schneider, O. (2010) Educação Physica: a arqueologia de um impresso. Vitória, ES: EDUFES.

Schneider, O. (2004) Entre a correção e a eficiência: mutações no significado da Educação Física nas décadas de 1930 e 1940 - um estudo a partir da revista Educação Physica. Revista Brasileira de Ciências do Esporte, Campinas, 25, (2) 39-54.

Schneider, O.; Ferreira Neto, A. (2008) Americanismo e a Fabricação do "Homem Novo": Circulação e Apropriação de Modelos Culturais na Revista Educação Physica (1932-1945). Movimento, 14, 135-159.

Silva, A. L. S. (2008) A perfeição expressa na carne: A educação física no projeto eugênico de Renato Khel - 1917 a 1929. (Dissertação mestrado) - Escola de Educação Física. Universidade Federal do Rio Grande do Sul, Porto Alegre, Brasil

Soares, C. L. (1990) O pensamento médico higienista e a Educação Física: 1850 a 1930. (Dissertação mestrado) Faculdade de Educação. Pontifícia Universidade Católica. São Paulo, Brasil.

Soares, C. L (1994) Educação física: raizes europeias e Brasil. Campinas, Brasil: Autores Associados.

Soares, C. L (2011) As roupas nas práticas corporais e esportivas: a educação do corpo entre o conforto, a elegância e a eficiência (1920-1940). Campinas, Brasil: Autores Associados.

Sousa, J. P. de. (2011) A cólera, a tuberculose e a varíola: as doenças e seus corpos. In: Priore, M; Amarantino, M. (Org.). História do corpo no Brasil. (pp.223-249) São Paulo, Brasil: Unesp.

Spes. (1943) Férias nas praias. Educação Physica, (74), 36.

Sugestôes para o seu fim de semana. (1945) Educação Physica, Rio de Janeiro, n. 87, p. 41.

Sugestôes para o seu fim de semana. (1945) Educação Physica, Rio de Janeiro, n. 88, p. 28-29.

Thomas, K. (1996) O homem e o mundo natural: mudanças de atitude em relação a plantas e aos animais (1500-1800). São Paulo, Brasil: Companhia das Letras.

Vieira, G. (1944) O tratamento hidroterápico na paralisia infantil. Educação Physica, (77), 56.

\section{Notas}

1 Apesar de a urbanização ter sido um fator importante na ascensão do higienismo no Brasil, não podemos atribuir uma relação de causa e efeito entre estes processos, uma vez que grande parte da população ainda habitava as zonas rurais e poucas eram as cidades brasileiras de grande porte neste período.

2 A ortografia da época foi mantida nas citações dos documentos

3 Renato Khel defendia desde práticas vistas como mais brandas, como o higienismo e sanitarismo das cidades, até a segregação das raças e o branqueamento da população, vistas como medidas mais radicais. Acreditava que os exercícios físicos eram importantes práticas eugênicas, já que permitiam a conquista de corpos fortes e vigorosos (Kinoshita, 2013; Silva, 2008; Soares, 1990). As atividades em meio à natureza apareciam como um complemento a este pensamento, já que no ideário eugênico, a cidade também se configurava como um local de degradação da raça e dos corpos.

Recepção: 27 Novembro 2017

Aprovação: 21 Dezembro 2017

La aceptación de colaboraciones por parte de la revista implica la cesión no exclusiva de los derechos patrimoniales de los autores a favor del editor, quien permite la reutilización, luego de su edición (postprint), bajo Licencia Creative Commons Atribución-NoComercial-CompartirIgual 4.0 Internacional (https:// creativecommons.org/licenses/by-nc-sa/4.0/).

CC BY-SA 